\title{
The 2021 Nobel Prize in Medicine and its relevance to autonomic medicine - and other updates on recent autonomic research
}

\author{
Mitchell G. Miglis ${ }^{1} \cdot$ Nicholas Larsen $^{1} \cdot$ Srikanth Muppidi ${ }^{1}$
}

Received: 3 November 2021 / Accepted: 3 November 2021 / Published online: 9 November 2021

(c) The Author(s), under exclusive licence to Springer-Verlag GmbH Germany 2021

Keywords Vasovagal $\cdot$ Midodrine $\cdot$ Mechanoreceptors $\cdot$ Nobel Prize, PIEZO, TRPV1 $\cdot$ Ampreloxetine $\cdot$ Verdiperstat

\section{The 2021 Nobel Prize in Medicine and its relevance to the autonomic field}

The 2021 Nobel Prize in Physiology or Medicine was awarded to David Julius at the University of California San Francisco (UCSF) and Ardem Patapoutian at Scripps Research, La Jolla for their discoveries of the mechanisms related to heat and mechanic perceptions [13]. We would like to highlight how their work is relevant and key to autonomic physiology and medicine. It is not frequent that a Nobel Prize awardee has a close relationship to the autonomic field. David Julius and his team were instrumental in the discovery of transient receptor potential (TRP) channels, a diverse family of channels that respond to a wide range of chemical and physical stimuli [3]. Perhaps, the most relevant TRP to autonomic physiology is the transient receptor potential vanilloid 1 (TRPV1) channel, also known as the capsaicin receptor, expressed predominantly in sensory nerves. TRPV 1 is activated by a vast range of stimuli, including noxious temperature, changes in $\mathrm{pH}$, as well as osmotic and mechanical stimuli [23]. In the gastrointestinal system, TRPV1-positive sensory nerves are responsible for the maintenance of mucosal integrity, $\mathrm{pH}$, intestinal motility, and visceral sensation [16]. In the cardiovascular system, sympathetic nerves innervating blood vessels are sensitive to capsaicin, and TRPV1 activation regulates blood pressure [17]. Interestingly, dietary capsaicin prevents hypertension [16, 24]. TRPV1 is also required for fluid homeostasis and normal osmoregulatory responses [18]. Beyond the

Srikanth Muppidi

muppidis@stanford.edu

1 Stanford Neurosciences Health Center, 213 Quarry Road, 2nd Floor, Palo Alto, CA 94304, USA improved understanding of autonomic regulation, this research has led to new therapeutic options for neuropathic pain. Resiniferatoxin, an extremely potent TRPV1 agonist (500 times more potent than capsaicin), is currently being tested as a therapeutic approach to treat severe pain due to metastatic cancer, osteoarthritis, and other causes. Ardem Patapoutian and his team contributed to our understanding of how mechanical stimuli are converted to electrical or chemical signals through a mechanically activated ion channel. His team identified multiple families of mechanoreceptors such as PIEZO and OSCA/TMEM63, which play a critical role in signal transmission including skin touch pressure sensation, and mechanosensing signals regulating blood vessels and airways [8]. There are few of these receptors, but, from an autonomic point of view, the key ones are Piezo1 and Piezo2. In one of our previous Autonomic Updates articles [11], we highlighted the efforts to understand the role of Piezo channels in baroreflex function. Piezo1 is prominently expressed in the cardiovascular system, whereas Piezo2 is expressed in sensory neurons. By developing a mouse model with PIEZO1 knockout, PIEZO2 knockout, and double knockout mice and testing different pharmacological challenges, researchers proposed that functional loss of Piezo receptors results in impaired baroreceptor function and that Piezo1 and Piezo2 receptors together are critical mechanoreceptors in baroreflex function [25]. Patapoutian and colleagues also described the relevance of Piezo2 in bladderfilling sensation and urination [9]. And, beyond baroreceptor function and micturition, Piezo channels have a critical role in the sensory, respiratory, gastrointestinal, and skeletal systems. In humans, rare loss-of-function mutations in PIEZO2 cause severe loss of proprioception. Combined loss of function of Piezo1 and Piezo2 presumably causes baroreflex failure in humans, although these patients are yet to be identified. While there are still many unanswered 
questions regarding the role of TRP and PIEZO channels in autonomic physiology and disease [1,21], we have no doubt that the 2021 Nobel Prize is well deserved.

\section{Midodrine for vasovagal syncope: repurposing an old drug for an age-old reflex}

Recurrent vasovagal syncope is the most common type of fainting, and can result in physical trauma and impaired quality of life [5]. Despite being frequent, vasovagal syncope remains difficult to treat in some patients. To date, there is no high-quality evidence that any medication is effective in the treatment of vasovagal syncope, although midodrine has shown some promise. In a recent study published in the Annals of Internal Medicine, Sheldon and colleagues attempted to determine whether midodrine could prevent vasovagal episodes [19]. The study was performed in 138 adult participants across 25 university hospitals in Canada, US, Mexico, and the UK. All participants had to have a Calgary Syncope Symptom Score of at least 2 and had to have fainted at least twice in the year prior to enrollment. Exclusion criteria included other causes of syncope, cardiac abnormalities, seizure disorder, urinary retention, hypertension, liver disease, glaucoma, postural tachycardia syndrome, or prior use of midodrine. Unless unavoidable, patients were not permitted to receive pacemakers, betablockers, other alpha-1-adrenergic agonists or antagonists, tricyclic antidepressants, serotonin reuptake inhibitors, scopolamine, theophylline, or fludrocortisone. Participants were randomly assigned and double-blinded to receive either midodrine or a placebo for 1 year. Participants started with $5 \mathrm{mg}$ of midodrine or a placebo three times daily, $4 \mathrm{~h}$ apart during daylight hours. Within the first 2 weeks, the dose was adjusted as tolerated within a range of $2.5 \mathrm{mg}$ twice daily to $10 \mathrm{mg}$ three times daily. If a participant could not tolerate the side effects despite dose reduction, he or she was withdrawn from the study. The primary outcome measure for this study was the proportion of patients with at least one syncopal episode during follow-up. Time to the first recurrence of syncope and frequency of syncope were also measured.

After taking the first dose, three midodrine and two placebo group participants withdrew. Of the remaining participants, $73 \%$ were women with a median age of 32 years. In the year before randomization, participants had a median of six syncopal episodes. During the study, 10 participants on midodrine and 11 on placebo were lost to follow-up. The remaining participants (56 in each group) were followed until the first syncope episode or for the full 12 months. The study found that 28 out of 66 (42\%) participants taking midodrine had recurrent syncope, compared to 41 out of $67(61 \%)$ in the placebo group. The absolute risk reduction was $19 \%$ and the number needed to prevent one patient from fainting was 5.3 (CI 2.8-47.6). The relative risk reduction for syncope in the midodrine group was 0.69 (CI 0.49-0.97, $p=0.035$ ). Midodrine was also associated with a longer time to first syncope (hazard ratio of 0.59 (CI 0.37-0.96), $p=0.035$ ). To make these promising results even more evident, there were 72 syncopal episodes in the midodrine group vs. 146 in the placebo group. The most common side effects were paresthesia and piloerection, followed by headache and nausea.

Studies performed many decades ago had shown that midodrine might prevent syncope triggered during in-office passive head-up tilt [6]. This is, however, the first multicenter, double-blinded, placebo-controlled trial that provides evidence that midodrine is indeed effective in reducing the likelihood of a syncope recurrence in younger patients with frequent syncope in a real-life setting. The major limitation of this study is its small sample size. In addition, due to the exclusion criteria, the study participants tended to be young and healthy, making the results less generalizable to older patients. Nevertheless, the study provides high-quality evident documenting the usefulness of midodrine in young patients with recurrent vasovagal syncope in the real-world setting.

\section{Failed clinical trials: a double hit for the autonomic community}

Clinical trials are expensive, time-consuming, and often unsuccessful, with an estimated 50\% of phase 3 trials failing to achieve efficacy in their primary endpoints [4]. Unfortunately, the autonomic community received the news of two failed phase 3 trials in September 2021: Theravance study 0169 of ampleroxetine in neurogenic orthostatic hypotension (nOH, NCT03750552) and Biohaven's M-STAR study of verdiperstat in multiple system atrophy (MSA, NCT03952806). These announcements were especially disappointing given the high burden caused by these two diseases and the limited treatment options available. Both were large, placebo-controlled studies with impressive enrollment numbers across multiple countries, with motivated patients and investigators. To make things direr, Theravance announced that they will be letting go most of their employees [22].

Why did these trials fail? There are many reasons why therapeutics fail to demonstrate efficacy in trials, including flawed trial design, inappropriate endpoints, lack of sufficient power (due to lower than expected enrollment or higher than expected patient dropout), and, of course, lack of therapeutic efficacy of the compound. Let us first look at verdiperstat, a myeloperoxidase (MPO) inhibitor that crosses the blood-brain barrier and may be neuroprotective by 
inhibiting MPO-induced oxidative stress and neuroinflammation. It is also being studied in amyotrophic lateral sclerosis, and a clinical trial with verdiperstat is currently ongoing (NCT04297683). The M-STAR study enrolled 300 patients with MSA across 30 sites in the U.S. and Europe, and randomized patients to 48 weeks of treatment with $300 \mathrm{mg}$ oral verdiperstat twice daily or placebo. There was no statistically significant difference between the verdiperstat and placebo groups in the primary endpoint, i.e., the change in the 'modified' Unified MSA Rating Scale (UMSARS) from baseline to week 48 [2]. In addition, there were no statistically significant differences in any of the secondary endpoints. One limitation of all MSA studies is difficulty in carefully phenotyping the disease. Diagnosing MSA is challenging at times, with a lack of definitive diagnostic biomarkers and overlapping clinical presentations with other neurodegenerative diseases, a topic we covered in our of our previous "Autonomic Updates" installments, in reference to another failed trial, the PROMESA green tea study [12]. Another limitation is the use of the UMSARS as a primary endpoint. A recent comprehensive review published in Clinical Autonomic Research earlier this year analyzed the many limitations of the UMSARS [15]. The authors noted how the UMSARS, while sensitive to change over time, has significant variability in standard deviation, thus requiring large cohorts ( $>100$ patients per group) and long study periods ( $\geq 1$ year) to achieve sufficient statistical power. In addition, some items are more likely to detect change than others, such as questions addressing posture/gait and dressing/hygiene. The UMSARS is also subject to a ceiling effect, more capable of detecting change early in the disease, when progression is more apparent, compared to more advanced disease states (trials often try to get around this by recruiting patients with milder forms of the disease). Furthermore, some of the UMSARS questions are ambiguous and may be affected by symptomatic treatment (orthostatic intolerance, for example), and thus may not accurately reflect changes in the underlying disease state. All these limitations highlight a need for a new and more sensitive clinical outcome measure in MSA.

What about ampleroxetine? The study also failed to meet statistical significance on the primary endpoint: change from baseline in the orthostatic hypotension questionnaire (OHQ) question \#1, which assesses the "dizziness, lightheadedness or feeling about to faint" symptoms when standing due to $\mathrm{nOH}$. This item has been used as an endpoint in the successful phase 3 droxidopa trials for $\mathrm{nOH}$; however, the failure of the ampreloxetine study again raises the issue of appropriate endpoints. It has been demonstrated that patients with nOH have poor symptom recognition and that the severity of orthostatic blood pressure drops may not correlate with their symptoms particularly if they also have depressive symptoms [10]. While looking at changes in orthostatic blood pressure instead may appear more reasonable, the health authorities, including the Food and Drug Administration, prioritize patient-reported outcomes, including symptoms and disability. Hence, the widespread use of the OHQ in clinical trials of nOH [14]. Theravance enrolled 195 patients with nOH caused by pure autonomic failure (PAF), Parkinson disease (PD), dementia with Lewy bodies (DLB), or MSA. This is another potential limitation of the study. Ampleroxetine is a norepinephrine transporter (NET) inhibitor, thus requiring intact NETs in the post-ganglionic autonomic nerves to have efficacy. Many patients with PD and DLB and most patients with PAF have severe post-ganglionic sympathetic denervation, which might prevent the efficacy of this therapy as suggested in studies using another NET, atomoxetine [20]. The trial design attempted to account for this by requiring seated orthostatic norepinephrine values $>100 \mathrm{pg} / \mathrm{mL}$ as in inclusion factor; however, samples were not required to be drawn from indwelling intravenous catheters, but rather from venipuncture, which may artificially increase values due to the stress response. Standing norepinephrine levels were not considered. It is tempting to hypothesize that the response to ampreloxetine might have been more robust if patients with more preserved post-ganglionic innervation (i.e., higher norepinephrine levels) might have been selected. A subgroup analysis might answer this. Note that the motivation to test ampreloxetine in a large trial in $\mathrm{nOH}$ came from a small phase 2 trial study, whose promising results are coincidentally published in this issue of Clinical Autonomic Research [7]. These results were obviously refuted in the phase 3 study.

Despite failing to meet their endpoints, these two trials are important. By illustrating potential limitations in their trial design, they force us to think differently about how we measure success when treating these disorders. Future research should focus on more accurate diagnostic and treatment-responsive biomarkers, as well as improved clinical outcome assessment tools. In the words of George Bernard Shaw, "science never solves a problem without creating ten more." Despite these difficulties, science inevitably marches forward, and, with renewed vision, we will overcome these barriers to see success in future therapeutics for autonomic disorders.

Funding None.

\section{Declarations}

Conflict of interest None.

\section{References}

1. Abboud FM (2021) Four evolving concepts in molecular and clinical autonomic research. Clin Auton Res 31:467-471

2. Biohaven Pharmaceuticals (2021) Press Release: Biohaven provides update on phase 3 trial and multiple system atrophy (MSA) 
program. In, https://www.biohavenpharma.com/investors/newsevents/press-releases/09-27-2021. Accessed 8 Nov 2021

3. Cao E, Liao M, Cheng Y, Julius D (2013) TRPV1 structures in distinct conformations reveal activation mechanisms. Nature 504:113-118

4. Fogel DB (2018) Factors associated with clinical trials that fail and opportunities for improving the likelihood of success: a review. Contemp Clin Trials Commun 11:156-164

5. Hall J, Bourne KM, Sheldon RS, Vernino S, Raj V, Ng J, Okamoto LE, Arnold AC, Bryarly M, Phillips L, Paranjape SY, Raj SR (2021) A comparison of health-related quality of life in autonomic disorders: postural tachycardia syndrome versus vasovagal syncope. Clin Auton Res 31:433-441

6. Kaufmann H, Saadia D, Voustianiouk A (2002) Midodrine in neurally mediated syncope: a double-blind, randomized, crossover study. Ann Neurol 52:342-345

7. Kaufmann H, Vickery R, Wang W, Kanodia J, Shibao CA, Norcliffe-Kaufmann L, Haumann B, Biaggioni I (2021) Safety and efficacy of ampreloxetine in symptomatic neurogenic orthostatic hypotension: a phase 2 trial. Clin Auton Res. https://doi.org/10. 1007/s10286-021-00827-0

8. Kefauver JM, Ward AB, Patapoutian A (2020) Discoveries in structure and physiology of mechanically activated ion channels. Nature 587:567-576

9. Marshall KL, Saade D, Ghitani N, Coombs AM, Szczot M, Keller J, Ogata T, Daou I, Stowers LT, Bonnemann CG, Chesler AT, Patapoutian A (2020) PIEZO2 in sensory neurons and urothelial cells coordinates urination. Nature 588:290-295

10. Martinez J, Palma JA, Norcliffe-Kaufmann L, Garakani A, Kaufmann H (2020) Impact of depressive symptoms on self-perceived severity of autonomic dysfunction in multiple system atrophy: relevance for patient-reported outcomes in clinical trials. Clin Auton Res 30:215-221

11. Miglis MG, Muppidi S (2019) Ion channels PIEZOs identified as the long-sought baroreceptor mechanosensors for blood pressure control, and other updates on autonomic research. Clin Auton Res 29:9-11

12. Miglis MG, Muppidi S (2019) The microbiome in autonomic medicine and other updates in recent autonomic research. Clin Auton Res 29:361-362

13. Nobel Prize Committee (2021) Press release: The Nobel Prize in Physiology or Medicine 2021. In, https://www.nobelprize.org/ prizes/medicine/2021/press-release/. Accessed 8 Nov 2021

14. Palma JA, Kaufmann H (2020) Clinical trials for neurogenic orthostatic hypotension: a comprehensive review of endpoints, pitfalls, and challenges. Semin Neurol 40:523-539
15. Palma JA, Vernetti PM, Perez MA, Krismer F, Seppi K, Fanciulli A, Singer W, Low P, Biaggioni I, Norcliffe-Kaufmann L, Pellecchia MT, Marti MJ, Kim HJ, Merello M, Stankovic I, Poewe W, Betensky R, Wenning G, Kaufmann H (2021) Limitations of the unified multiple system atrophy rating scale as outcome measure for clinical trials and a roadmap for improvement. Clin Auton Res 31:157-164

16. Peng J, Li YJ (2010) The vanilloid receptor TRPV1: role in cardiovascular and gastrointestinal protection. Eur J Pharmacol 627:1-7

17. Phan TX, Ton HT, Gulyas H, Porszasz R, Toth A, Russo R, Kay MW, Sahibzada N, Ahern GP (2020) TRPV1 expressed throughout the arterial circulation regulates vasoconstriction and blood pressure. J Physiol 598:5639-5659

18. Sharif Naeini R, Witty MF, Seguela P, Bourque CW (2006) An $\mathrm{N}$-terminal variant of Trpv 1 channel is required for osmosensory transduction. Nat Neurosci 9:93-98

19. Sheldon R, Faris P, Tang A, Ayala-Paredes F, Guzman J, Marquez M, Morillo CA, Krahn AD, Kus T, Ritchie D, Safdar S, Maxey C, Raj SR, investigators P (2021) Midodrine for the prevention of vasovagal syncope: a randomized clinical trial. Ann Intern Med 174:1349-1356

20. Shibao CA, Palma JA, Celedonio JE, Martinez J, Kaufmann H, Biaggioni I (2021) Predictors of the pressor response to the norepinephrine transporter inhibitor, atomoxetine, in neurogenic orthostatic hypotension. Hypertension 78:525-531

21. Stocker SD, Sved AF, Andresen MC (2019) Missing pieces of the Piezo1/Piezo2 baroreceptor hypothesis: an autonomic perspective. J Neurophysiol 122:1207-1212

22. Theravance Biopharma (2021) Press release: Theravance Biopharma, INC. Announces top-line results from a phase 3 study of ampreloxetine in patients with symptomatic neurogenic orthostatic hypotension. In, https://investor.theravance.com/news-relea ses/news-release-details/theravance-biopharma-inc-announcestop-line-results-phase-3. Accessed 8 Nov 2021

23. White JP, Urban L, Nagy I (2011) TRPV1 function in health and disease. Curr Pharm Biotechnol 12:130-144

24. Yang D, Luo Z, Ma S, Wong WT, Ma L, Zhong J, He H, Zhao Z, Cao T, Yan Z, Liu D, Arendshorst WJ, Huang Y, Tepel M, Zhu Z (2010) Activation of TRPV1 by dietary capsaicin improves endothelium-dependent vasorelaxation and prevents hypertension. Cell Metab 12:130-141

25. Zeng WZ, Marshall KL, Min S, Daou I, Chapleau MW, Abboud FM, Liberles SD, Patapoutian A (2018) PIEZOs mediate neuronal sensing of blood pressure and the baroreceptor reflex. Science 362:464-467 